\title{
Kinematical Limit Analysis for a Slope Reinforced with One Row of Stabilizing Piles
}

\author{
Shiguo Xiao, ${ }^{1,2,3}$ Hong He, ${ }^{1}$ and Jinxiu Zeng ${ }^{1}$ \\ ${ }^{1}$ State-Province Joint Engineering Laboratory of Spatial Information Technology of High-Speed Rail Safety, Chengdu 610031, China \\ ${ }^{2}$ Key Laboratory of High-Speed Railway Engineering, Ministry of Education, Southwest Jiaotong University, Chengdu 610031, China \\ ${ }^{3}$ School of Civil, Mining and Environmental Engineering, University of Wollongong, Wollongong, NSW 2522, Australia
}

Correspondence should be addressed to Shiguo Xiao; xiaoshiguo@swjtu.cn

Received 29 July 2016; Revised 23 October 2016; Accepted 15 November 2016

Academic Editor: Jose J. Muñoz

Copyright (C) 2016 Shiguo Xiao et al. This is an open access article distributed under the Creative Commons Attribution License, which permits unrestricted use, distribution, and reproduction in any medium, provided the original work is properly cited.

\begin{abstract}
Stabilizing piles are commonly used to improve slope stability. The load that a pile should sustain and the associated slip surface under a prescribed factor of safety are two critical design parameters in practice. Based on the kinematically admissible failure mechanism, a limit analysis approach is introduced, which considers two potential slip surfaces that individually lie in the upslope and downslope of the piles. The explicit formulas for the upslope thrust force and downslope resistance on a pile are derived, which enables the calculation of the maximum load on a pile and the corresponding critical slip surfaces using a computer program. The maximum load and critical slip surfaces under a design factor of safety are mainly affected by soil properties and five other parameters: location of the pile row, dip angle of the slope face, action point and dip angle of the force, and improvement coefficient of the slope stability. The relevant quantitative calculation can be performed using the proposed method. Moreover, the possible failure with the upslope soil surpassing the pile top under a specified design factor of safety is significantly illustrated in the paper, which is helpful in the rational determination of the location of the pile row.
\end{abstract}

\section{Introduction}

The stabilizing pile is one of the important retaining structures used to enhance slope stability. To design a soil slope that is reinforced with piles, engineers and technicians are concerned with two significant parameters: the load that a pile should sustain and the location of the slip surface for the slope with piles under a prescribed factor of safety. Many investigators have studied this problem, and some methods have been proposed. To date, these methods can be classified into three categories. First, some methods based on the limit equilibrium theory were provided [1-5]. Second, some studies conducted using numerical simulation methods can also be used to solve this problem [6-12]. Third, investigations based on the kinematical limit analysis approach presented different means to design a slope with the piles [13-16]. To provide a close-formed analysis solution, this paper follows the third method. Although plastic flowing through the piles can occur when discrete piles are used to stabilize soil slopes, as an essential hypothesis in the third method, a piled soil slope with a slip surface does not always occur in practical engineering. On the contrary, the situation of two different slip surfaces on both sides of the pile row is actually acceptable in most cases [17]. In particular, this mode is suitable for the condition that there is no plastic flowing for soils surrounding piles. Therefore, unlike the existing method, where the entire slip surface of a slope with piles is assumed to break the piles or soils surrounding piles are in plastic flowing state, the present method adopts two different slip surfaces in the upslope and downslope soil of the pile row.

Based on the kinematical limit analysis principle, the maximum load that a pile should afford and the corresponding pair of critical slip surfaces, which individually lie on the upslope and downslope of the pile row, were determined under a design factor of safety. Moreover, the present method can also analyze whether a failure where the upslope soil mass of the pile row surpasses the pile tops can occur under the design condition, which is not illustrated in previous related 


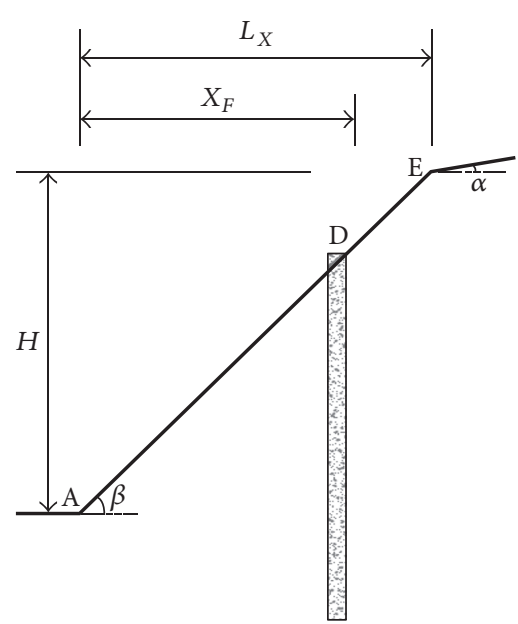

(a)

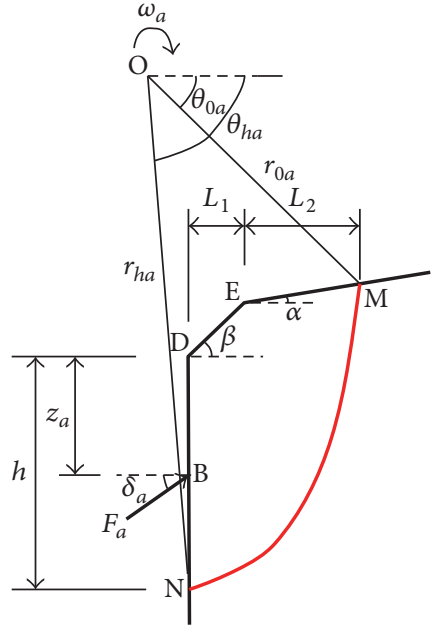

(b)

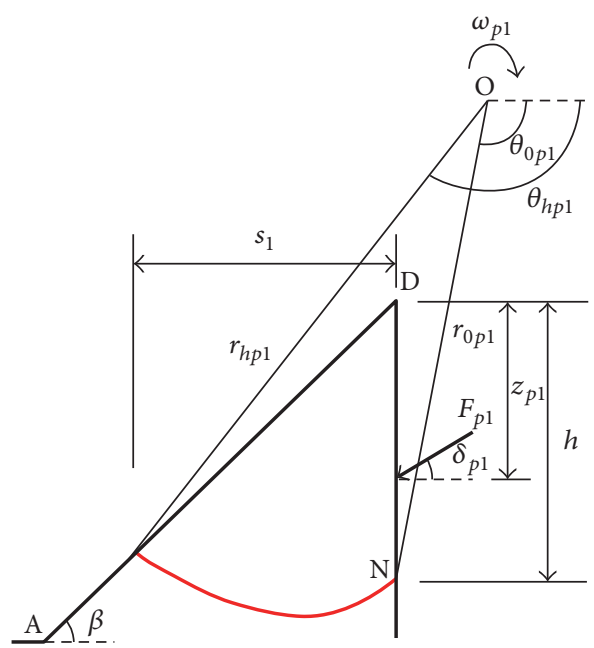

(c)

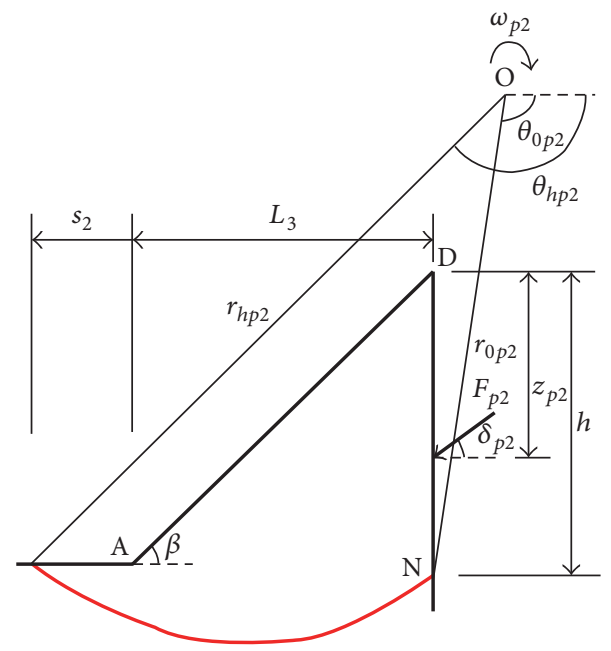

(d)

FIGURE 1: Analysis models: (a) sketch map of a soil slope; (b) kinematical limit analysis model for the soil mass in the upslope of a pile row; ((c) and (d)) kinematical limit analysis model for the soil mass in the downslope of the pile row when $s_{1} \leq H / \tan \beta$ and $s_{1}>H / \tan \beta$, respectively.

studies. The present method and some existing methods were compared to verify the acceptability of the proposed method.

\section{Analysis Model and Derivation}

As shown in Figure 1(a), a soil slope is reinforced with one row of stabilizing piles. For a stabilizing pile, there are an upslope thrust force and a downslope resistance on the upslope and downslope faces, respectively. For the sake of simplifying the analysis process, some assumptions are adopted as follows.

(1) The upslope and downslope potential sliding masses of the piled slope are assumed to move as rigid bodies, respectively. And the upslope and downslope faces of the piles are regarded individually as velocity discontinuity interfaces. But the sliding depth $h$ of the upslope sliding body at the location of the pile is identical with that of the downslope sliding body.
(2) The piles are long enough for avoiding the failure mode of the piled slope with slip surface passing by their bottoms.

(3) Considering the stabilizing pile being mostly designed as elastic body in practical engineering, it is provided herein that the stabilizing pile is not in failure state under the two forces.

The difference between the upslope thrust and the downslope resistance, which is called the net force here, is the load that the pile should sustain. In other words, for any specified factor of safety of the slope stability, the corresponding net force is the design load on the pile. Therefore, to determine the design load, we can calculate the upslope thrust force and downslope resistance. However, it is notably clear that the net force varies with the increase in depth of different potential pairs of slip surface below the pile top. Thus, to validate that the reinforced slope is of the desired factor of 
safety, there is the maximum net force, which can be called the net limiting force [18], which the pile must bear. The net limiting force is calculated under the assumption that the piles behave as a fixed wall, and this force is used to design the piles from a structural viewpoint. To this end, a linear elastic behaviour is often assumed for the piles in order to evaluate the internal forces that arise in them. Considering the high levels of loading to which the piles are generally subjected, more comprehensive constitutive models that account for the nonlinear behaviour of the piles could be also used [19].

According to the kinematically admissible failure mechanism [20], the question can be formulated as finding the maximum value of the upslope thrust force and the associated minimum value of the downslope resistance, which can lead to the maximum difference between them. The corresponding pair of slip surfaces is exactly the critical pair of slip surfaces. Thus, the problem can be solved using the following procedures:

(1) Prescribing any depth of the potential slip surface below the pile top.

(2) Calculating the upslope thrust force and downslope resistance on the pile.

(3) Determining the net limiting force on the pile.

(4) Repeating (1) to (3) to obtain a number of net limiting forces related to various sliding depths and comparing all of the forces and determining the maximum value of the net limiting force and the corresponding critical pair of slip surfaces.

2.1. Upslope Thrust Force on a Pile. As shown in Figure 1(b), if a potential slip surface in the upslope mass of the pile is assumed to be logarithmic spiral, the formula of the log-spiral slip line can be expressed as (see Notation for all symbol explanations)

$$
r_{h a}=r_{0 a} \cdot e^{\left(\theta_{a}-\theta_{0 a}\right) \tan \phi},
$$

where a relevant geometric relationship is provided in the Appendix (see (A.1) and (A.2)).

The depth of the slip surface below the pile top is prescribed as $h$. For the potential upslope sliding mass, based on the upper bound theorem of kinematical limit analysis [20], one obtains

$$
W_{G a}+W_{F a}=E_{d 1} .
$$

The work rate of gravity can be derived as [20]

$$
W_{G a}=\gamma r_{0 a}^{3} \omega_{a}\left(f_{1}-f_{2}-f_{3}-f_{4}\right),
$$

where the coefficients $f_{i}(i=1$ to 4$)$ are described in the Appendix (see (A.7) and (A.10)).

The work rate of the external force, which is exerted by the pile, can be derived as

$$
\begin{aligned}
& W_{F a}=-F_{a} \omega_{a}\left[\left(r_{h a} \sin \theta_{h a}-h+z_{a}\right) \cos \delta_{a}\right. \\
& \left.\quad+r_{h a} \cos \theta_{h a} \sin \delta_{a}\right] .
\end{aligned}
$$

In addition, the dissipation rate of internal energy can be derived as

$$
E_{d 1}=\frac{c r_{0 a}^{2} \omega_{a}}{2 \tan \phi}\left[e^{2\left(\theta_{h a}-\theta_{0 a}\right) \tan \phi}-1\right] .
$$

Substituting (3), (4), and (5) into (2), one obtains

$$
\begin{aligned}
& F_{a} \\
& =\frac{\gamma r_{0}^{3}\left(f_{1}-f_{2}-f_{3}-f_{4}\right)-\left(c r_{0 a}^{2} / 2 \tan \phi\right)\left[e^{2\left(\theta_{h a}-\theta_{0 a}\right) \tan \phi}-1\right]}{\left(r_{h a} \sin \theta_{h a}-h+z_{a}\right) \cos \delta_{a}+r_{h a} \cos \theta_{h a} \sin \delta_{a}} .
\end{aligned}
$$

The physical mechanism for the analysis model shown in Figure 1(b) can be expressed that, in the case of any prescribed sliding depth $h$, the thrust force on a pile reaches its maximum value when the rigid sliding soil body with a log-spiral slip surface is in limit state. So the corresponding mathematical problem can be described as finding the maximum thrust force on a pile during variation of a log-spiral slip surface under the condition that $h$ is prescribed. Meanwhile, $\theta_{0 a}$ and $\theta_{h a}$ are independent variables related to $F_{a}$. Thus, for any prescribed $h$, the maximum upslope thrust force on a pile $F_{a}$ is calculated using (6) and the following equation:

$$
\begin{gathered}
\frac{\partial F_{a}}{\partial \theta_{0 a}}=0 \\
\frac{\partial F_{a}}{\partial \theta_{h a}}=0 .
\end{gathered}
$$

2.2. Downslope Resistance on a Pile. For the potential downslope sliding mass (see Figure 1(c)), the corresponding slip surface is also assumed as a log-spiral line and expressed as

$$
r(\theta)=r_{0 p 1} \cdot e^{\left(\theta_{p 1}-\theta_{0 p 1}\right) \tan \phi},
$$

where the relevant geometric relationship is specified in the Appendix (see (A.3) and (A.4)).

Considering the practical possibility [17] and theoretical reasonability, the depth of the potential slip surface below the pile top under this condition is also equal to $h$. Similarly, according to the upper bound theorem, there is

$$
W_{G p 1}+W_{F p 1}=E_{d 2},
$$

where the work rate of gravity can be derived as

$$
W_{G p 1}=\gamma r_{0 p 1}^{3} \omega_{p 1}\left(f_{5}-f_{6}-f_{7}\right),
$$

where the coefficients $f_{i}(i=5$ to 7$)$ are indicated in the Appendix (see (A.11) and (A.13)).

The work rate of the external force exerted by the pile can be derived as

$$
\begin{aligned}
& W_{F p 1}=F_{p 1} \omega_{p 1}\left[\left(r_{0 p 1} \sin \theta_{0 p 1}-h+z_{p 1}\right) \cos \delta_{p 1}\right. \\
& \left.\quad+r_{0 p 1} \cos \theta_{0 p 1} \sin \delta_{p 1}\right] .
\end{aligned}
$$

Likewise, the dissipation rate of internal energy can be expressed as

$$
E_{d 2}=\frac{c r_{0 p 1}^{2} \omega_{p 1}}{2 \tan \phi}\left\{e^{\left[2\left(\theta_{h p 1}-\theta_{0 p 1}\right) \tan \phi\right]}-1\right\} .
$$


Substituting (10), (11), and (12) into (9), one obtains

$$
\begin{aligned}
& F_{p 1} \\
& =\frac{\left(c r_{0 p 1}^{2} / 2 \tan \phi\right)\left[e^{2\left(\theta_{h p 1}-\theta_{0 p 1}\right) \tan \phi}-1\right]-\gamma r_{0 p 1}^{3}\left(f_{5}-f_{6}-f_{7}\right)}{\left(r_{0 p 1} \sin \theta_{0 p 1}-h+z_{p 1}\right) \cos \delta_{p 1}+r_{0 p 1} \cos \theta_{0 p 1} \sin \delta_{p 1}} .
\end{aligned}
$$

The physical mechanism for the analysis model shown in Figure 1(c) can be expressed that, in the case of any prescribed sliding depth $h$, the resisting force on a pile reaches its minimum value when the rigid sliding soil body with a log-spiral slip surface is in limit state. So the corresponding mathematical problem can be described as finding the minimum resisting force on a pile during variation of a logspiral slip surface under the condition that $h$ is prescribed. Meanwhile, $\theta_{0 p 1}$ and $\theta_{h p 1}$ are independent variables related to $F_{p 1}$. Thus, for any prescribed $h$, the minimum downslope resisting force on a pile $F_{p 1}$ is calculated using (13) and the following equation:

$$
\begin{aligned}
& \frac{\partial F_{p 1}}{\partial \theta_{0 p 1}}=0 \\
& \frac{\partial F_{p 1}}{\partial \theta_{h p 1}}=0 .
\end{aligned}
$$

However, it should be noted that if $s_{1}>H / \tan \beta$, the shape of potential downslope sliding mass obviously varies (see Figure 1(d)), which makes the downslope resistance not equal to the result from (13). Then, the corresponding downslope resistance on the pile is calculated as follows.
As shown in Figure 1(d), the log-spiral slip line can be expressed as

$$
r_{h p 2}=r_{0 p 2} \cdot e^{\left(\theta_{p 2}-\theta_{0 p 2}\right) \tan \phi}
$$

where the relevant geometric relationship is shown in the Appendix (see (A.5) and (A.6)).

Correspondingly, according to the upper bound theorem, one obtains

$$
W_{G p 2}+W_{F p 2}=E_{d 3}
$$

where the work rate of gravity can be derived as

$$
W_{G p 2}=\gamma r_{0 p 2}^{3} \omega_{p 2}\left(f_{8}-f_{9}-f_{10}-f_{11}\right) \text {. }
$$

The coefficients $f_{i}(i=8$ to 11$)$ are shown in the Appendix (see (A.14) and (A.17)).

The work rate of the external force exerted by the pile can be derived as

$$
\begin{aligned}
& W_{F p 2}=F_{p 2} \omega_{p 2}\left[\left(r_{0 p 2} \sin \theta_{0 p 2}-h+z_{p 2}\right) \cos \delta_{p 2}\right. \\
& \left.\quad+r_{0 p 2} \cos \theta_{0 p 2} \sin \delta_{p 2}\right] .
\end{aligned}
$$
as

The dissipation rate of internal energy can be expressed

$$
E_{d 3}=\frac{c r_{0 p 2}^{2} \omega_{p 2}}{2 \tan \phi}\left[e^{2\left(\theta_{h p 2}-\theta_{0 p 2}\right) \tan \phi}-1\right] .
$$

Then, substituting (17), (18), and (19) into (16), one obtains

$$
F_{p 2}=\frac{-\gamma r_{0 p 2}^{3}\left(f_{8}-f_{9}-f_{10}-f_{11}\right)+\left(c r_{0 p 2}^{2} / 2 \tan \phi\right)\left[e^{2\left(\theta_{h p 2}-\theta_{0 p 2}\right) \tan \phi}-1\right]}{\left(r_{0 p 2} \sin \theta_{0 p 2}-h+z_{p 2}\right) \cos \delta_{p 2}+r_{0 p 2} \cos \theta_{0 p 2} \sin \delta_{p 2}} .
$$

Similarly, for the analysis model shown in Figure 1(d), the minimum downslope resisting force on a pile $F_{p 2}$ is calculated using (20) and the following equation

$$
\begin{aligned}
& \frac{\partial F_{p 2}}{\partial \theta_{0 p 2}}=0 . \\
& \frac{\partial F_{p 2}}{\partial \theta_{h p 2}}=0
\end{aligned}
$$

Hence, for any prescribed $h$, the minimum downslope resistance on the pile can be determined.

2.3. Net Limiting Force on a Pile. Considering the practical significance, the horizontal component of the net force on a pile is generally much more essential than the vertical component. Hence, the horizontal component is the critical scope of the present work. The horizontal component on the pile can be expressed as

$$
F_{n}=F_{a} \cos \delta_{a}-F_{p 1} \cos \delta_{p 1} .
$$

If $s_{1}>H / \tan \beta,(22)$ should be expressed as

$$
F_{n}=F_{a} \cos \delta_{a}-F_{p 2} \cos \delta_{p 2} .
$$

Thus, according to (22) and (23), we obtain the net limiting force (i.e., maximum value of $F_{n}$ ) when any design factor of safety can be introduced into the aforementioned solution procedures using the following equations. In other words, we can substitute $c_{d}$ and $\phi_{d}$ from (24) for $c$ and $\phi$ in the aforementioned procedures.

$$
\begin{aligned}
c_{d} & =\frac{c}{F_{s}} . \\
\phi_{d} & =\arctan \left(\frac{\tan \phi}{F_{s}}\right)
\end{aligned}
$$



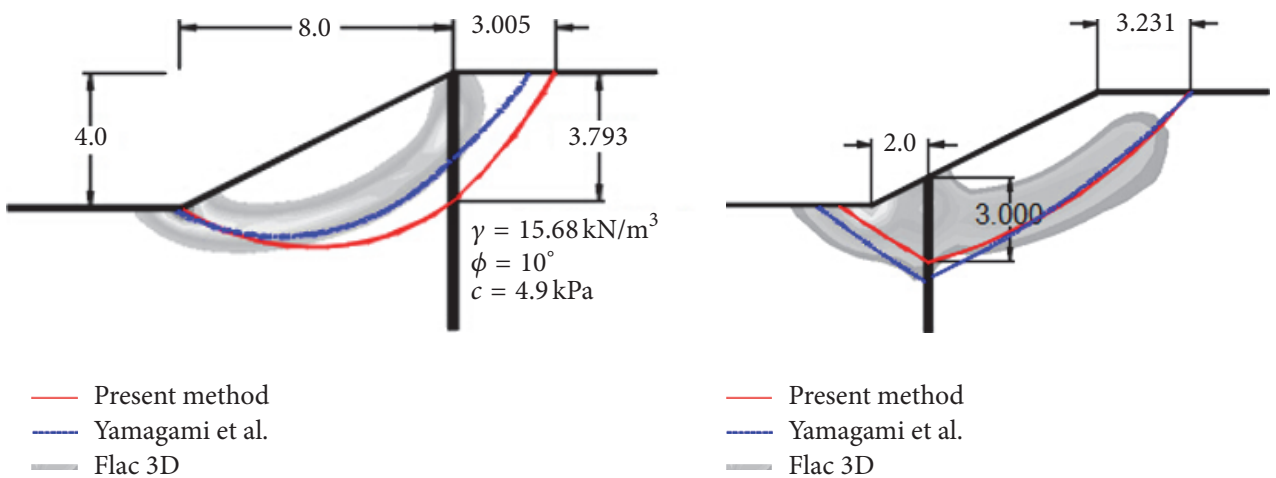

(a1)

(a2)

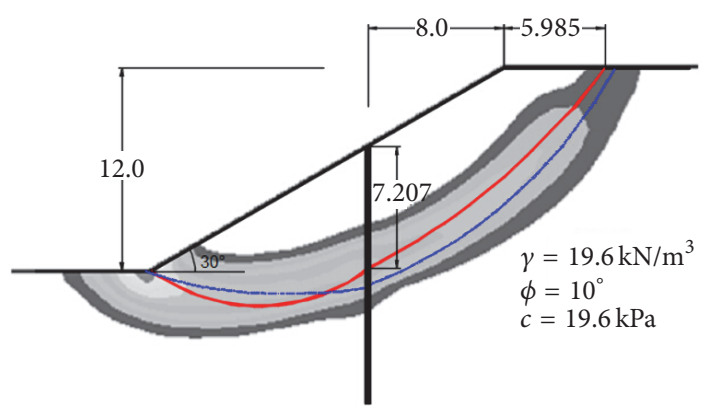

_ Present method
_ Yamagami et al.
Flac 3D

(b)

FIgURE 2: Critical slip surfaces, which were obtained using the present method and two other methods (unit: m).

It should be noted that, for any prescribed $h$, the net limiting force can be computed exclusively. That is to say, the net limiting force is the function of the sliding depth $h$. According to practical requirements in the design of stabilizing piles used to reinforce a slope, the maximum value of the net limiting force should be determined. From the mathematical point of view, the maximum net limiting force can be found using

$$
\frac{\partial F_{n}}{\partial h}=0
$$

The entire procedures can be conducted using a computer program, which was performed by the authors using the Visual C++ 2008 program.

\section{Verification Examples}

Three dimensionless factors are defined in (26)-(28) to conveniently explain the problem. Coefficient $\eta$ is cited and shown in (29) to express the improvement extent of the slope stability after a slope was reinforced with a pile row [13]. To demonstrate the rationality of the present method, three examples are cited here: a soil slope with $4 \mathrm{~m}$ height (see Figures 2(a1) and 2(a2)) and a soil slope with $12 \mathrm{~m}$ height (see Figure 2(b)). As shown in Figure 2, the critical slip surfaces that were calculated using the limit equilibrium method (LEM) [17] and the proposed method are fairly close for the three slope examples. Moreover, the results of the present method are consistent with the intense shearing band that was obtained using the Flac 3D numerical simulation. The net limiting forces that were obtained using the LEM and the proposed method are also provided in Table 1. The result shows that the proposed method gives larger $K_{F \max }$ than the LEM. The reason is possibly that the results of the kinematical limit analysis are the upper bound solution. However, the results of the LEM are neither the upper bound solution nor the lower bound solution [21]. The $K_{h}$ values of the two methods are close except for the example in Figure 2(a1). Figure 2 and Table 1 also show that the critical slip surfaces and net limiting forces are clearly affected by the location of the pile row. To further illustrate the problem, the slope examples [4] were calculated by the proposed method. As shown in Figure 3, $K_{F \max }$ clearly varies with the increase of the location of the pile row as indicated by a dimensionless coefficient $X_{F} / L_{X}$. Figure 3 also shows that the proposed method produces larger results than the existing method based on kinematical limit analysis, where only one continuous slip surface is assumed in the piled slope [15]. Figure 4 shows the comparison results of the present method and an existing method for another example [13], 


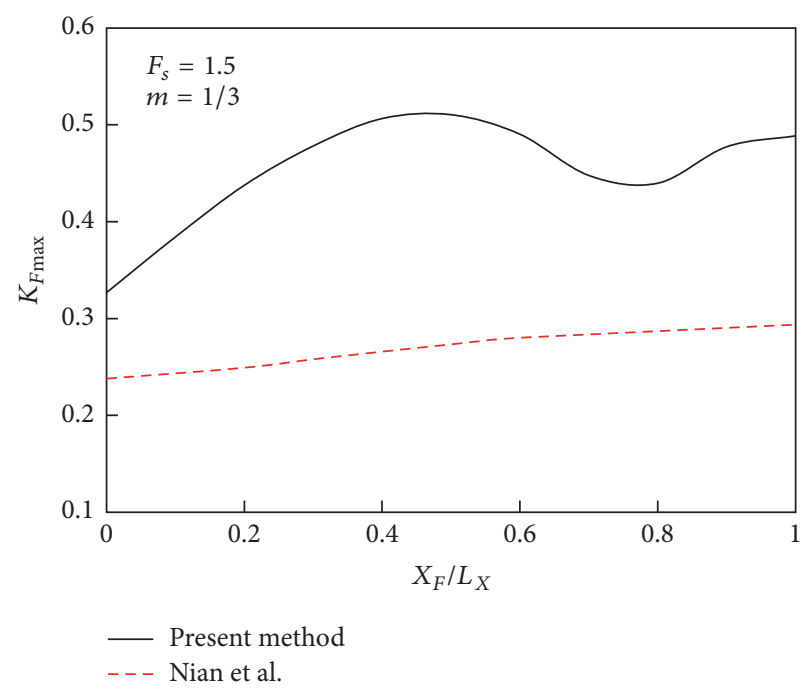

(a)

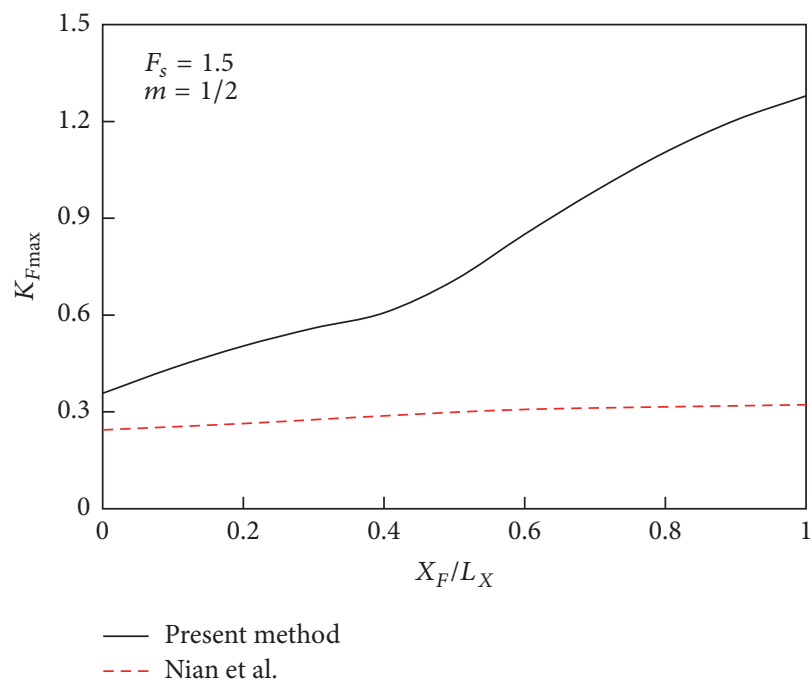

(b)

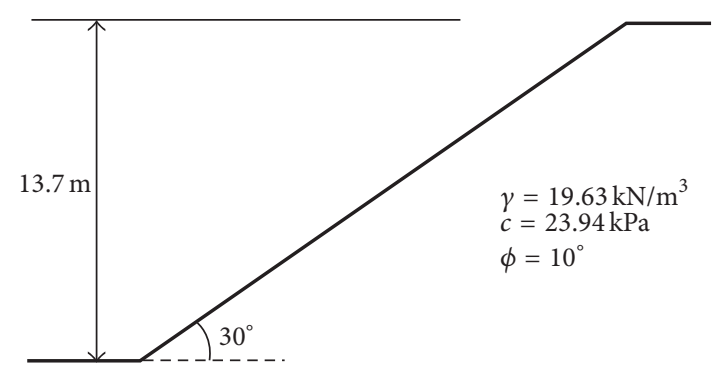

(c)

FIGURE 3: Comparisons of $K_{F \max }$ between the present method and a published method.

which also indicates a similar relationship between the two methods. Additionally, Table 2 shows detailed comparisons of the dimensionless net limiting force $K_{F \max }$, where the design factor of safety is 1.5, of the present method with the published results. The comparisons specifically indicate the relationship between the proposed method and the existing methods.

$$
\begin{aligned}
K_{F} & =\frac{F_{n}}{\left(0.5 \gamma H^{2}\right)} \\
K_{F \max } & =\frac{F_{n \max }}{\left(0.5 \gamma H^{2}\right)} \\
K_{h} & =\frac{h_{c}}{H} \\
\eta & =\frac{F_{s}}{F_{s 0}} .
\end{aligned}
$$

\section{Parameter Study and Discussion}

The pile location significantly affects the pile-reinforced slope. On one hand, as previously mentioned, the net limiting force on a pile is closely linked to the pile location. On the other hand, the pile location significantly affects the stability of the slope with piles. In other words, whether a
TABLE 1: Comparisons of the detailed results in Figure 2 of the present method and an existing method.

\begin{tabular}{lccccc}
\hline \multirow{2}{*}{ Examples } & \multirow{2}{*}{$X_{F} / L_{X}$} & \multicolumn{2}{c}{ Present method } & \multicolumn{2}{c}{ Yamagami et al., 2000 } \\
& & $K_{F \max }$ & $K_{h}$ & $K_{F \max }$ & $K_{h}$ \\
\hline (a1) & 1 & 0.2333 & 0.9483 & 0.0829 & 0.6265 \\
(a2) & 0.25 & 0.1385 & 0.7500 & 0.1268 & 0.8945 \\
(b) & 0.615 & 0.1974 & 0.6006 & 0.1127 & 0.6686 \\
\hline
\end{tabular}

TABLE 2: Comparisons of the dimensionless net limiting force $K_{F \max }$ with published results $\left(F_{s}=1.5\right)$.

\begin{tabular}{ccccc}
\hline$m$ & $X_{F} / L_{X}$ & $\begin{array}{c}\text { Ausilio et al., } \\
2001\end{array}$ & $\begin{array}{c}\text { Nian et al., } \\
2008\end{array}$ & $\begin{array}{c}\text { Present } \\
\text { method }\end{array}$ \\
\hline $1 / 3$ & 0.5774 & 0.2796 & 0.2809 & 0.4949 \\
$1 / 3$ & 0.5 & - & 0.2750 & 0.5105 \\
$1 / 2$ & 0.5 & - & 0.3000 & 0.7082 \\
\hline
\end{tabular}

pile-reinforced slope can attain the desired factor of safety significantly depends on the pile location. The slope example in Figure 3 [4] was used to illustrate the effect. As shown in Figure 5(a), the net limiting force $\left(h=h_{c}\right)$ and net force at pile top $(h=0)$ vary with the pile location. However, it should be noted that the thrust force on the pile top is positive if $X_{F} / L_{X}$ is less than $X_{F C} / L_{X}$, which is equal to 0.385 , 


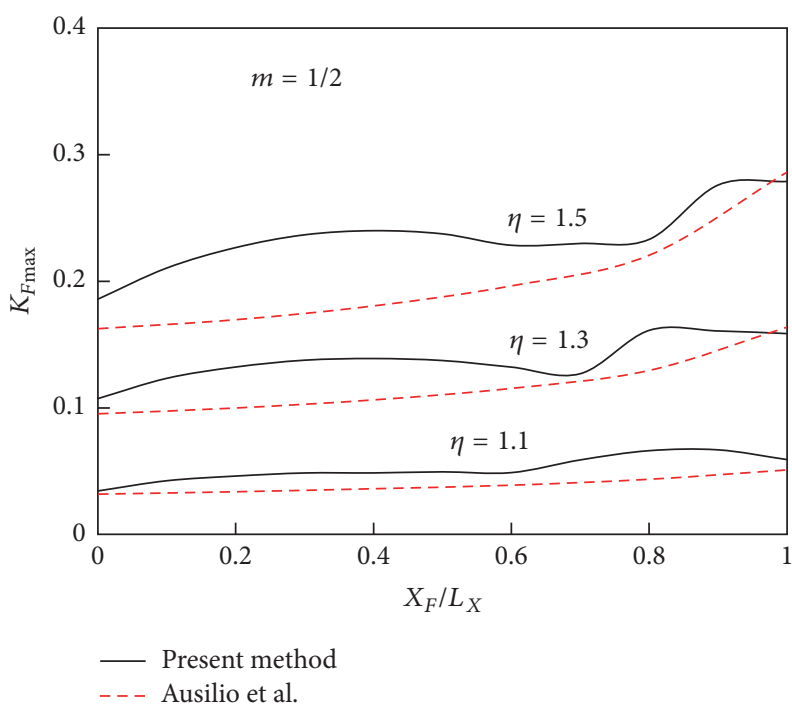

(a)

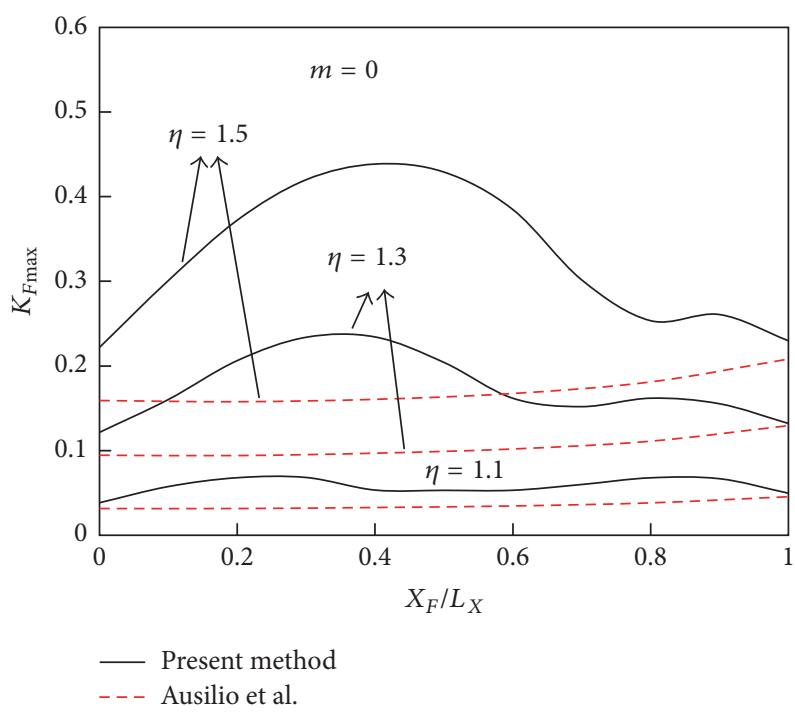

(c)

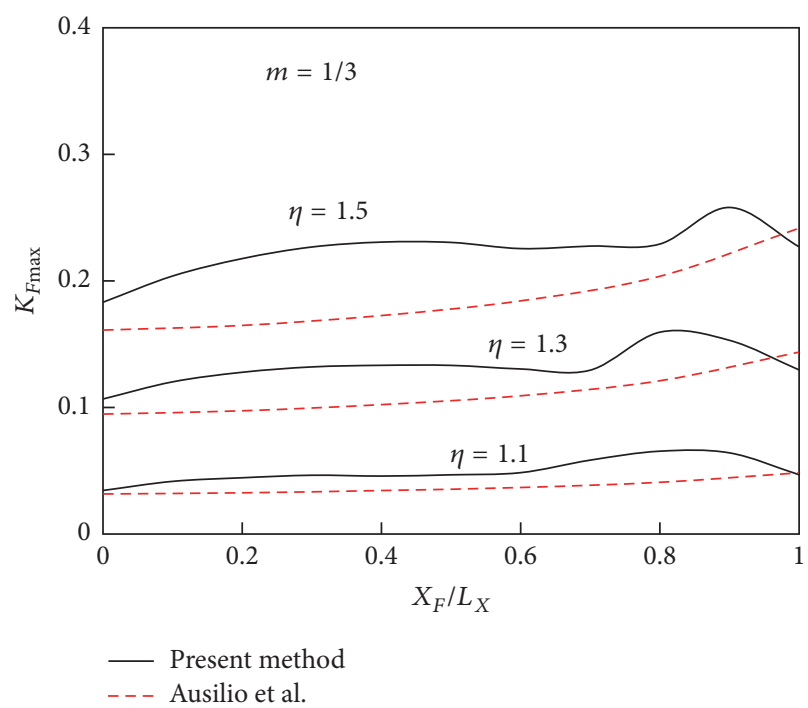

(b)

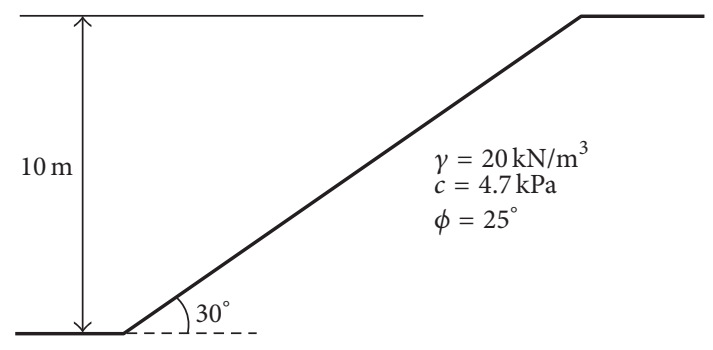

(d)

FIGURE 4: Comparisons of $K_{F \max }$ between the present method and another published method.

which implies that, under this condition, the reinforced slope is actually in a failure state with the upslope soil surpassing the pile top when the specified factor of safety is $F_{s}=1.5$ (see Figure 5(c)). Therefore, $X_{F} / L_{F}$ should be more than 0.385 to satisfy the requirement that the design factor of safety is 1.5 for the slope. Thus, considering the minimum net limiting force, the optimal $X_{F} / L_{X}$ should be 0.77 . The corresponding dimensionless factor $K_{h}$ of the depth of the slip surface below the pile top is approximately 0.95 (see Figure 5(b)), and $K_{F \max }$ is 0.44 .

In addition, based on the aforementioned derivation, $m$, $\beta, \eta$, and $\delta$ affect the net limiting force and corresponding depth of the slip surface below the pile top. Thus, these parameters are discussed as follows.

(1) The Coefficient of Action Point of the Net Limiting Force $m$. A previous study indicated that $m$ hardly affected $K_{F \max }$
[13]. However, the present study reveals different results. For example, for the same slope [4], Figures 6(a1), 6(b1), and 6(c1) show that $K_{F \max }$ obviously varies when $m$ is $1 / 3$ and $1 / 2$. Correspondingly, $K_{h}$ clearly varies if $m$ varies (see Figures 6(a2), 6(b2), and 6(c2)). In particular, the differences are much more remarkable if $X_{F} / L_{X}$ is more than $X_{F C} / L_{X}$ (see Figure 7 and the dashed line in Figure 6), which is the minimum $X_{F} / L_{X}$ to ensure that the reinforced slope is not in a failure state with the upslope soil surpassing the pile tops.

(2) Improvement Coefficient of the Slope Stability $\eta$. As shown in Figures 6(d1) and 6(d2), $K_{F \max }$ is closely related to $\eta$. $K_{F \max }$ increases with the increase in $\eta$. Additionally, $K_{h}$ is clearly affected by $\eta$ (see Figures 8(a) and 8(b)). For different $\eta$ values, $K_{h}$ nonlinearly varies with the increase in $X_{F} / L_{X} \cdot X_{F C} / L_{X}$ increases with the increase in $\eta$ (see Figure 7). The results for 


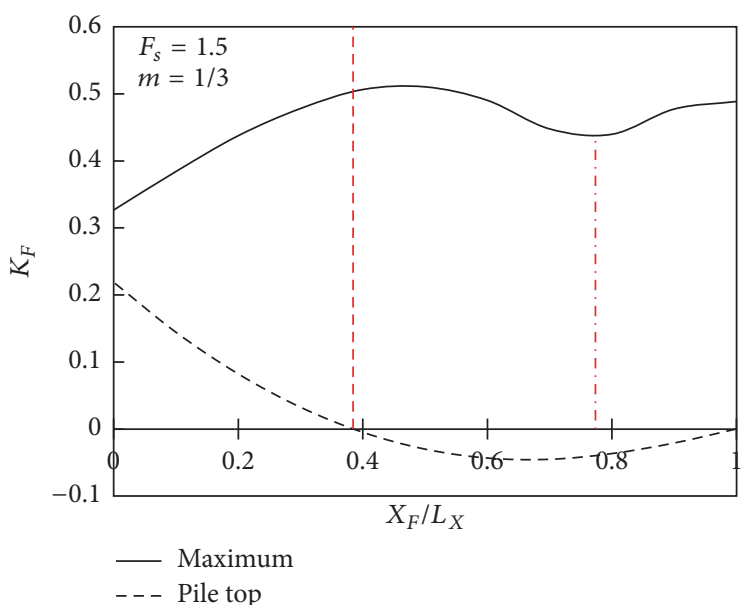

(a)

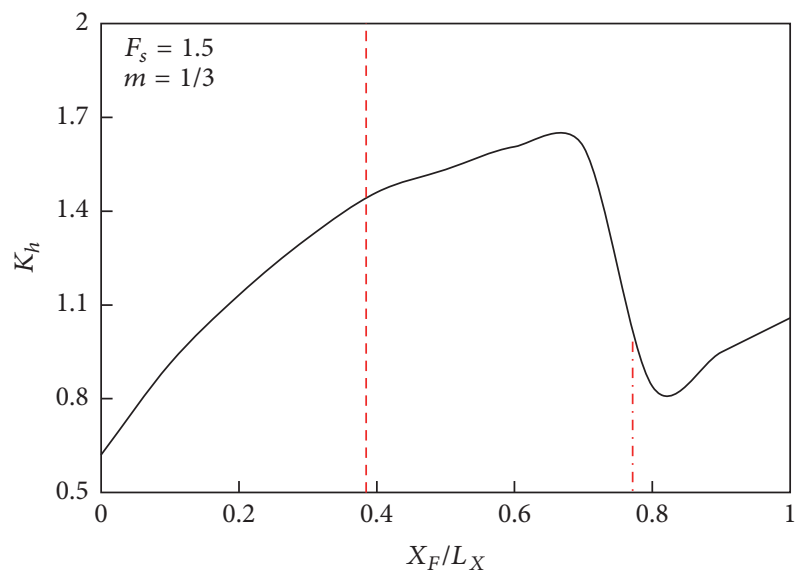

(b)

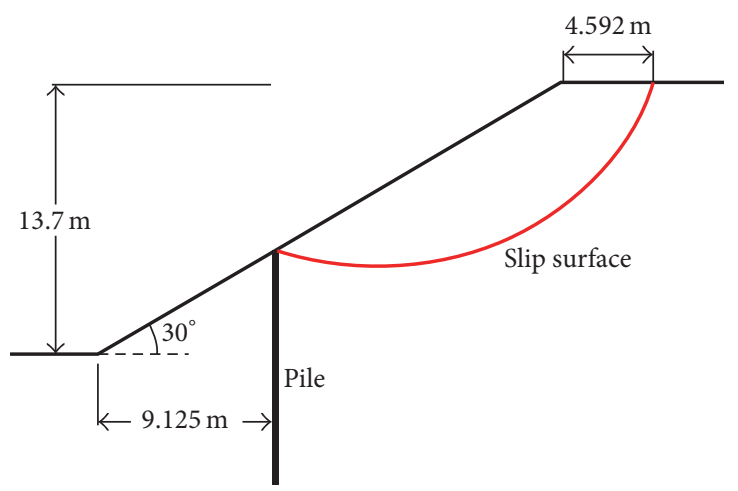

(c)

Figure 5: Calculation results of the proposed method for the slope example in Figure 3. (a) Relationship between $K_{F}$ and $X_{F} / L_{X}$; (b) relationship between $K_{h}$ and $X_{F} / L_{X}$; (c) failure mode with the upslope soil surpassing the pile top when $X_{F} / L_{X}=0.385$ in the case of $F_{s}=1.5$.

another example in Figure 9 [9] also show similar effects (see Figures 9(a1), 9(a2), 9(b1), 9(c1), and 9(c2)).

(3) Dip Angle of the Slope Face $\beta . K_{F \max }, K_{h}$, and $K_{F t}$ are associated with $\beta$ at different $X_{F} / L_{X}$. As shown in Figures 10(a), 10(b), and 10(c) for the slope example in Figure 3, $K_{F \max }$, $K_{h}$, and $X_{F C} / L_{X}$ obviously decrease with the increase in $\beta$. However, $K_{F t}$ does not clearly vary with the increase in $\beta$. In particular, $K_{F t}$ is almost constant with $\beta$ when $X_{F} / L_{X}$ is more than 0.5 .

(4) Dip Angle of the Net Limiting Force $\delta$. As shown in Figures 11(a1), 11(a2), 11(b1), and 11(b2), where the dashed line indicates the location of $X_{F C} / L_{X}$, two related slope examples in Figures 3 and 9 were individually calculated using the present method to reveal the effect of $\delta\left(\delta_{a}=\delta_{p 1}=\delta_{p 2}=\delta\right)$ on $K_{F \max }$ and $K_{h}$. The result indicates that both $K_{F \max }$ and $K_{h}$ decrease to some extent with the increase in $\delta$. For different $\delta$, both $K_{F \max }$ and $K_{h}$ nonlinearly vary with the increase in $X_{F} / L_{X}$.

\section{Concluding Remarks}

A relatively rigorous method based on the kinematical limit analysis principle is introduced to analyze a soil slope reinforced with one row of stabilizing piles. Relative to the existing methods, the proposed method assumes a more realistic failure mode, where two slip surfaces individually arise in the soil mass of the upslope and downslope of the pile row.

The present method provides a close-formed solution to the net limiting force on a pile and the corresponding critical slip surfaces under a prescribed factor of safety. In addition to the soil properties, these results are obviously affected by the pile location, improvement coefficient of the slope stability, dip angles of the slope face, action point, and dip angle of the net limiting force.

In particular, the proposed method also reveals that a soil slope with piles may be likely in a failure state where the soil mass in the upslope of the piles surpasses the pile tops under a design factor of safety if the location of the pile row is not proper. To make sure that the soil slope with piles satisfies the 


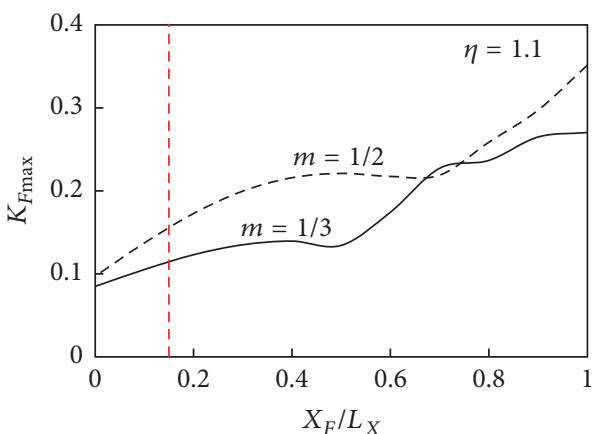

(a1)

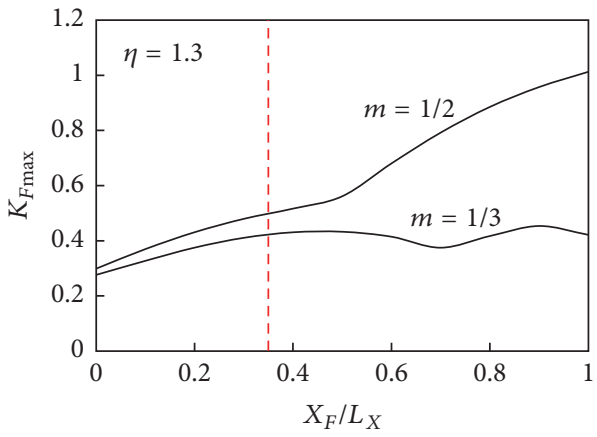

(b1)

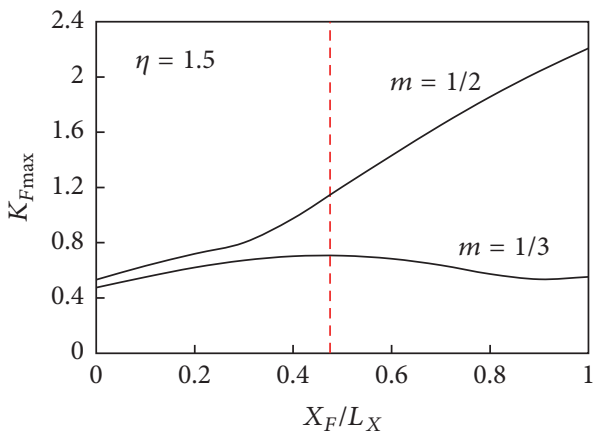

(c1)

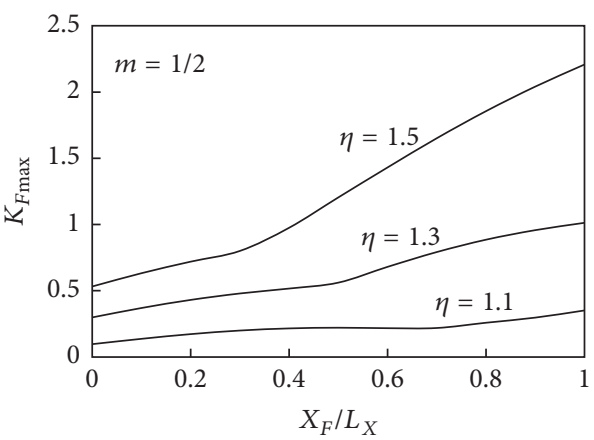

(d1)

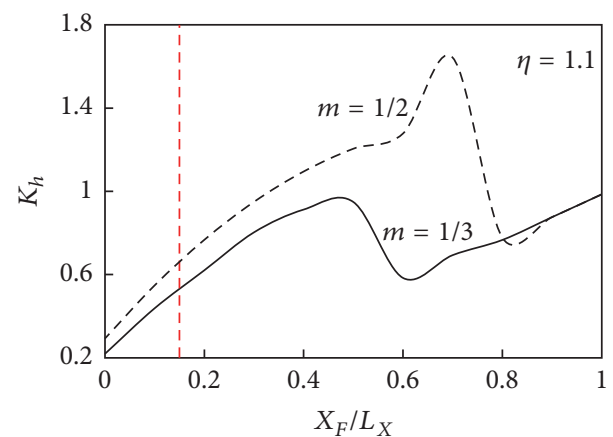

(a2)

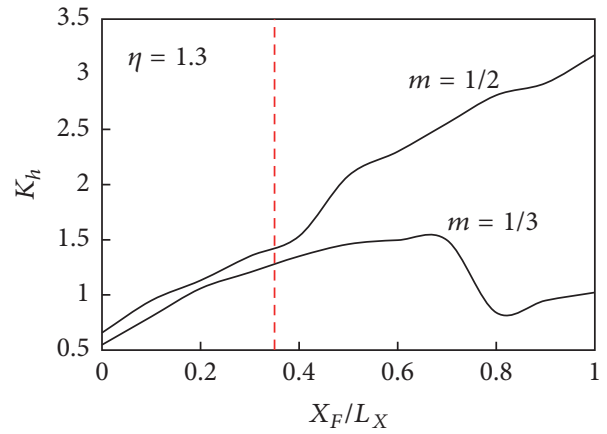

(b2)

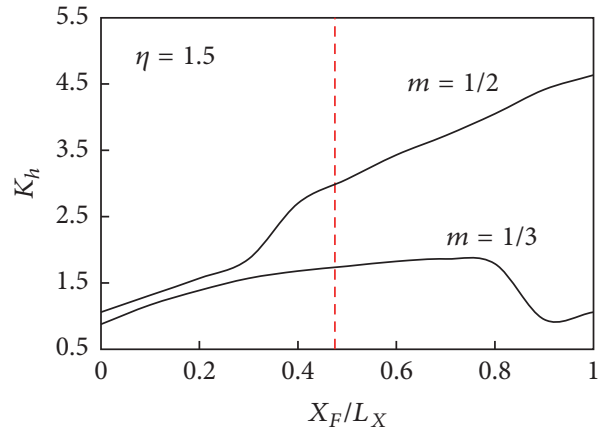

(c2)

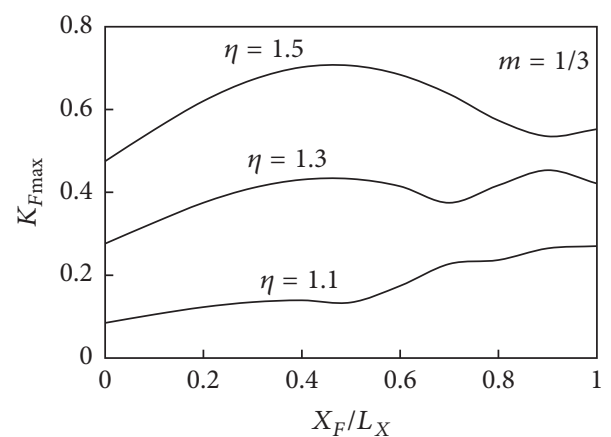

(d2)

Figure 6: Effects of $m, \eta$, and $X_{F} / L_{X}$ on $K_{F \max }$ and $K_{h}$ for the slope example in Figure 3. 


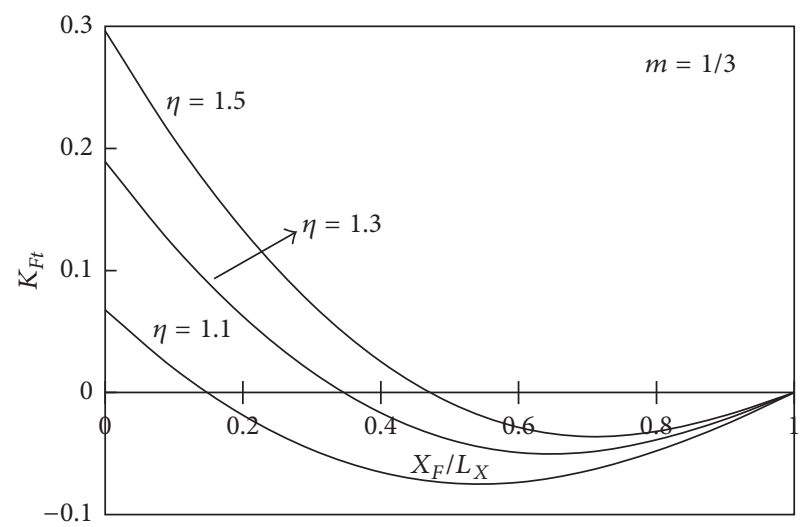

\begin{tabular}{lccc}
\hline$\eta$ & 1.1 & 1.3 & 1.5 \\
\hline$X_{F C} / L_{X}$ & 0.150 & 0.350 & 0.475 \\
\hline
\end{tabular}

Figure 7: Influence of $\eta$ and $X_{F} / L_{X}$ on $K_{F t}$ for the slope example shown in Figure 3.

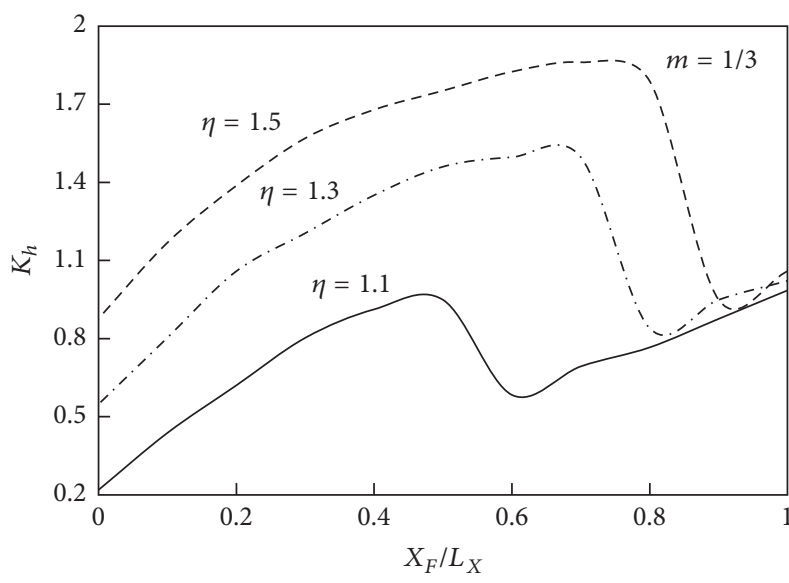

(a)

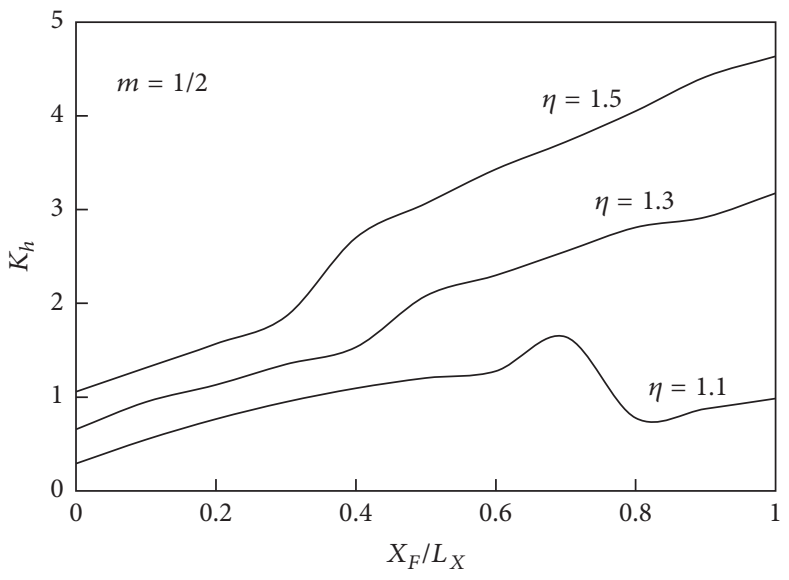

(b)

Figure 8: Effects of $\eta$ and $X_{F} / L_{X}$ on $K_{h}$ for the slope example in Figure 3.

requirement of the desired factor of safety, the pile row should be installed in the location where the thrust force on the top of the pile row is less than zero. In fact, the suitable or optimal location of the pile row is not certainly near the toe of a slope.

\section{Appendix}

In Figures 1(b), 1(c), and 1(d), there is the following geometric relationship:

$$
\begin{aligned}
L_{2} & =\frac{\left(h+L_{1} \tan \beta\right)\left[\cos \theta_{0 a}-e^{\left(\theta_{h a}-\theta_{0 a}\right) \tan \phi} \cdot \cos \theta_{h a}\right]-L_{1}\left[e^{\left(\theta_{h a}-\theta_{0 a}\right) \tan \phi} \cdot \sin \theta_{h a}-\sin \theta_{0 a}\right]}{\left[e^{\left(\theta_{h a}-\theta_{0 a}\right) \tan \phi} \cdot \sin \theta_{h a}-\sin \theta_{0 a}\right]-\left[\cos \theta_{0 a}-e^{\left(\theta_{h a}-\theta_{0 a}\right) \tan \phi} \cdot \cos \theta_{h a}\right] \tan \alpha} \\
r_{0 a} & =\frac{L_{1}+L_{2}}{\cos \theta_{0 a}-e^{\left(\theta_{h a}-\theta_{0 a}\right) \tan \phi} \cdot \cos \theta_{h a}} \\
s_{1} & =r_{0 p 1} \cos \theta_{0 p 1}-r_{h p 1} \cos \theta_{h p 1} \\
\frac{h}{r_{0 p 1}}= & \sin \theta_{0 p 1}+\tan \beta \cos \theta_{0 p 1}-e^{\left(\theta_{h p 1}-\theta_{0 p 1}\right) \tan \phi} \cdot\left(\sin \theta_{h p 1}+\tan \beta \cos \theta_{h p 1}\right) \\
s_{2}= & \frac{\left(h-L_{3} \tan \beta\right)\left[\cos \theta_{0 p 2}-e^{\left(\theta_{h p 2}-\theta_{0 p 2}\right) \tan \phi} \cdot \cos \theta_{h p 2}\right]-L_{3}\left[\sin \theta_{0 p 2}-e^{\left(\theta_{h p 2}-\theta_{0 p 2}\right) \tan \phi} \cdot \sin \theta_{h p 2}\right]}{\sin \theta_{0 p 2}-e^{\left(\theta_{h p 2}-\theta_{0 p 2}\right) \tan \phi} \cdot \sin \theta_{h p 2}} \\
r_{0 p 2}= & \frac{L_{3}+s_{2}}{\cos \theta_{0 p 2}-e^{\left(\theta_{h p 2}-\theta_{0 p 2}\right) \tan \phi} \cdot \cos \theta_{h p 2}} \cdot
\end{aligned}
$$




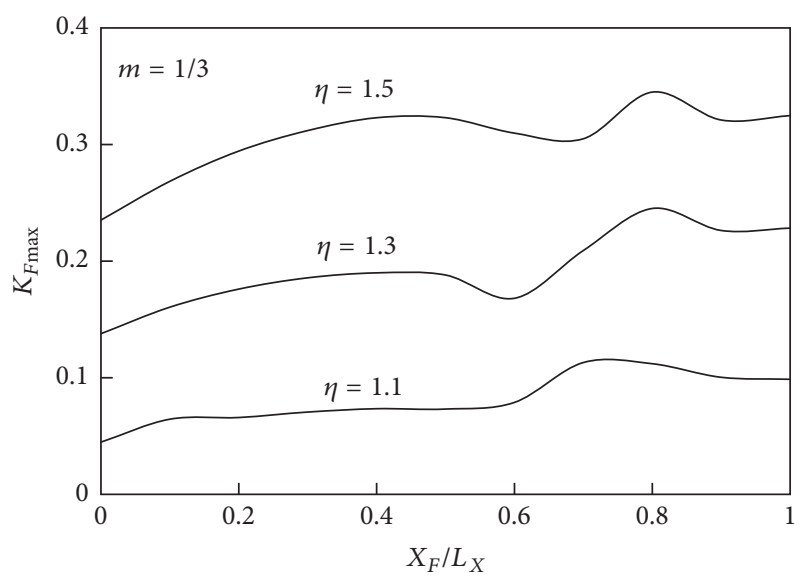

(a1)

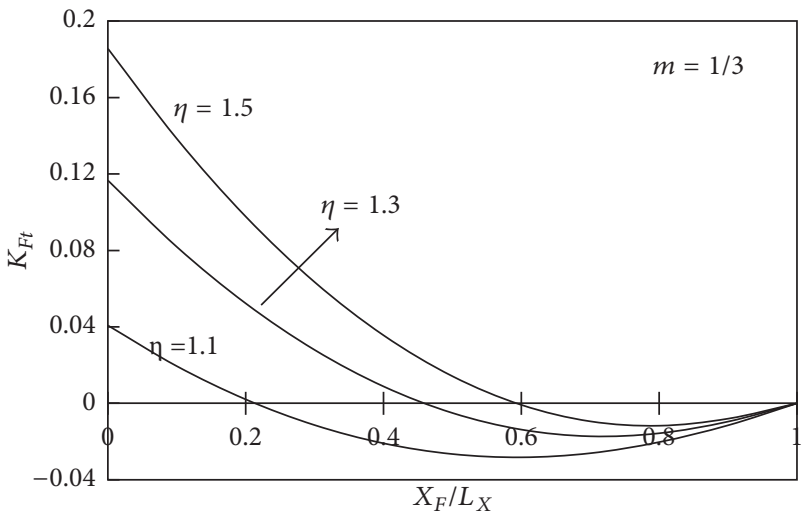

(b1)

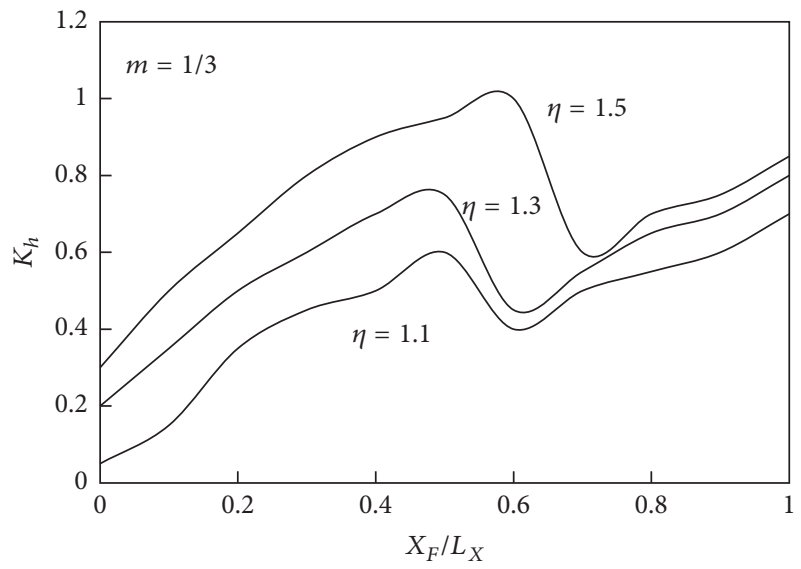

(c1)

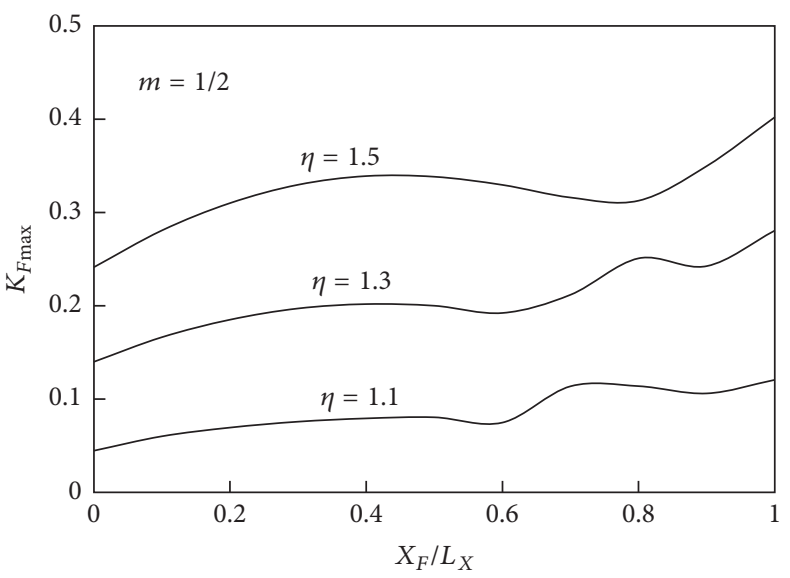

(a2)

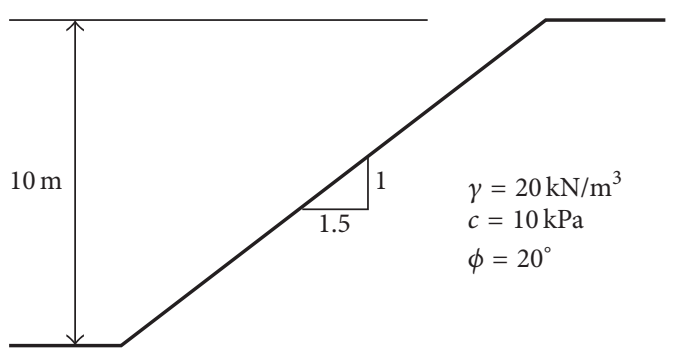

(b2)

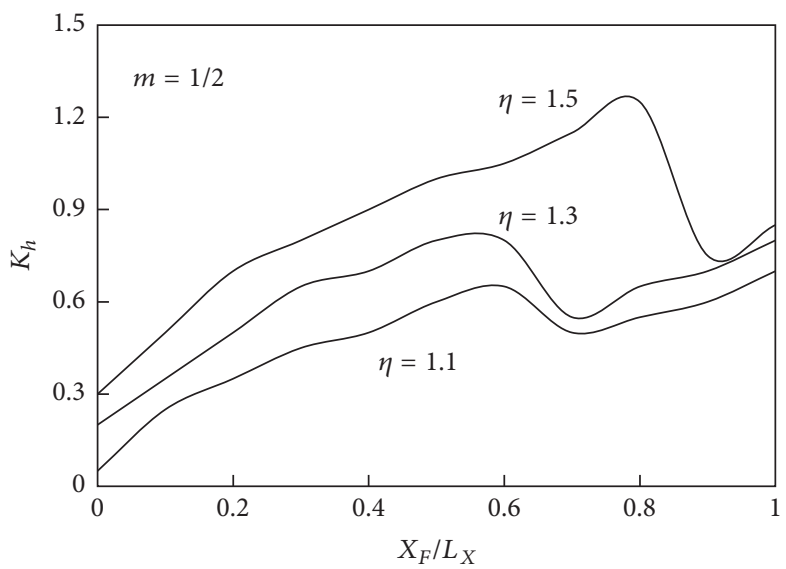

(c2)

Figure 9: Effects of $\eta, m$, and $X_{F} / L_{X}$ on $K_{F \max }, K_{F t}$, and $K_{h}$ for another slope example.

According to the concept of the gravity work rate [20], the coefficients of the gravity work rate can be derived and expressed as follows:

$$
\begin{aligned}
& f_{1}=\frac{\left(3 \tan \phi \cdot \cos \theta_{h a}+\sin \theta_{h a}\right) \cdot e^{3\left(\theta_{h a}-\theta_{0 a}\right) \tan \phi}-3 \tan \phi \cdot \cos \theta_{0 a}-\sin \theta_{0 a}}{3\left(1+9 \tan ^{2} \phi\right)} \\
& f_{2}=\frac{L_{2} \sin \left(\alpha+\theta_{0 a}\right) \cdot\left(2 r_{0 a} \cos \theta_{0 a}-L_{2}\right)}{6 r_{0 a}^{2} \cos \alpha}
\end{aligned}
$$




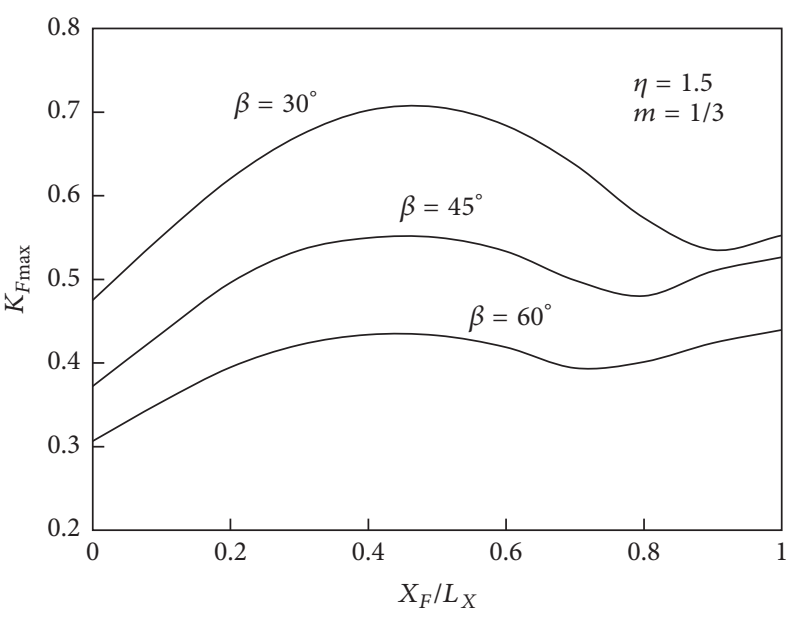

(a)
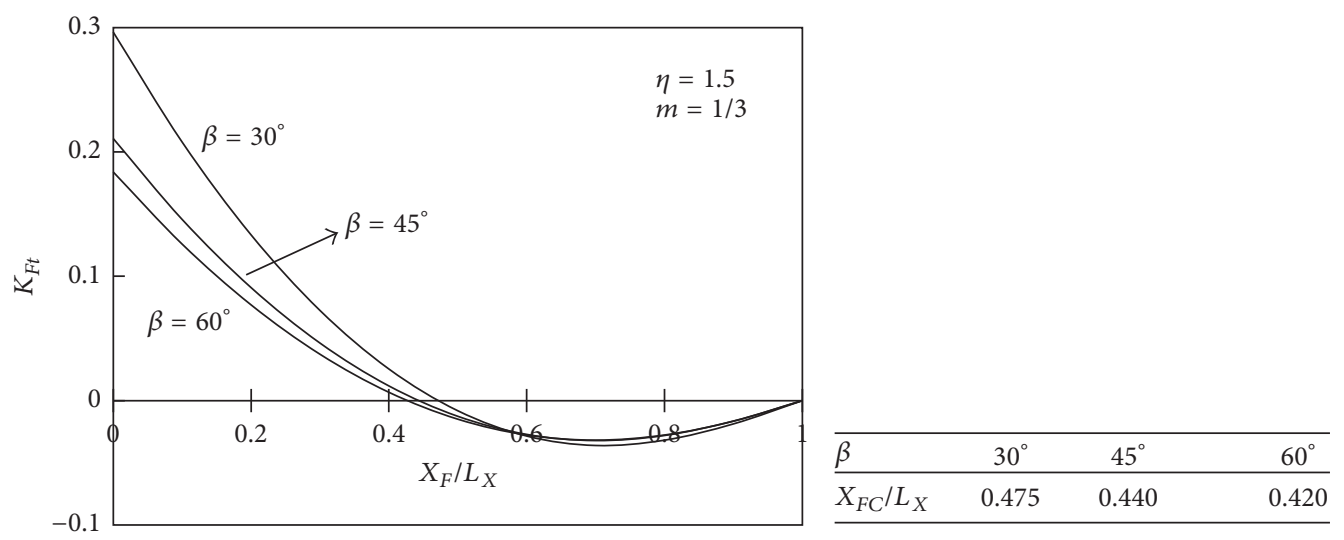

(c)

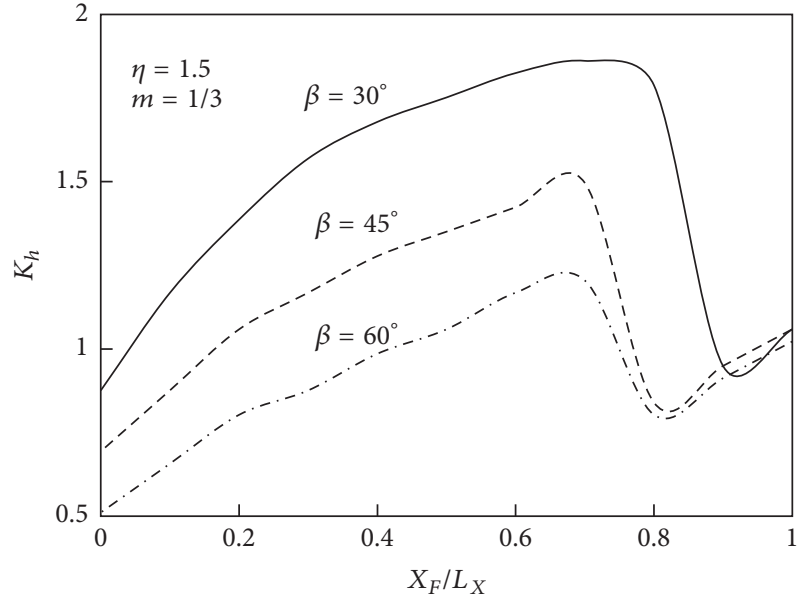

(b)

Figure 10: Effects of $\beta$ and $X_{F} / L_{X}$ on $K_{F \max }, K_{h}$, and $K_{F t}$ for the slope example in Figure 3.

$f_{3}=\frac{1}{6 r_{0 a}^{3}}\left\{L_{1}\left[r_{0 a} \sin \theta_{0 a}+L_{2} \tan \alpha\right]+\left(r_{0 a} \cos \theta_{0 a}-L_{2}\right) L_{1} \tan \beta\right\}\left[2\left(r_{0 a} \cos \theta_{0 a}-L_{2}\right)-L_{1}\right]$

$f_{4}=\frac{h e^{\left(\theta_{h a}-\theta_{0 a}\right) \tan \phi} \cdot r_{h a} \cos ^{2} \theta_{h a}}{3 r_{0 a}^{2}}$

$f_{5}=\frac{\left(3 \tan \phi \cos \theta_{h p 1}+\sin \theta_{h p 1}\right) e^{\left[3\left(\theta_{h p 1}-\theta_{0 p 1}\right) \tan \phi\right]}-3 \tan \phi \cos \theta_{0 p 1}-\sin \theta_{0 p 1}}{3\left(1+9 \tan ^{2} \phi\right)}$

$f_{6}=-\frac{1}{3} \frac{h}{r_{0 p 1}} \cos ^{2} \theta_{0 p 1}$

$f_{7}=\frac{s_{1}}{6 r_{0 p 1} \cos \beta}\left[\cos \theta_{0 p 1}+e^{\left(\theta_{h p 1}-\theta_{0 p 1}\right) \tan \phi} \cdot \cos \theta_{h p 1}\right] \cdot e^{\left(\theta_{h p 1}-\theta_{0 p 1}\right) \tan \phi} \cdot \sin \left(\beta+\theta_{h p 1}\right)$

$f_{8}=\frac{\left(3 \tan \phi \cdot \cos \theta_{h p 2}+\sin \theta_{h p 2}\right) \cdot e^{3\left(\theta_{h p 2}-\theta_{0 p 2}\right) \tan \phi}-3 \tan \phi \cdot \cos \theta_{0 p 2}-\sin \theta_{0 p 2}}{3\left(1+9 \tan ^{2} \phi\right)}$ 

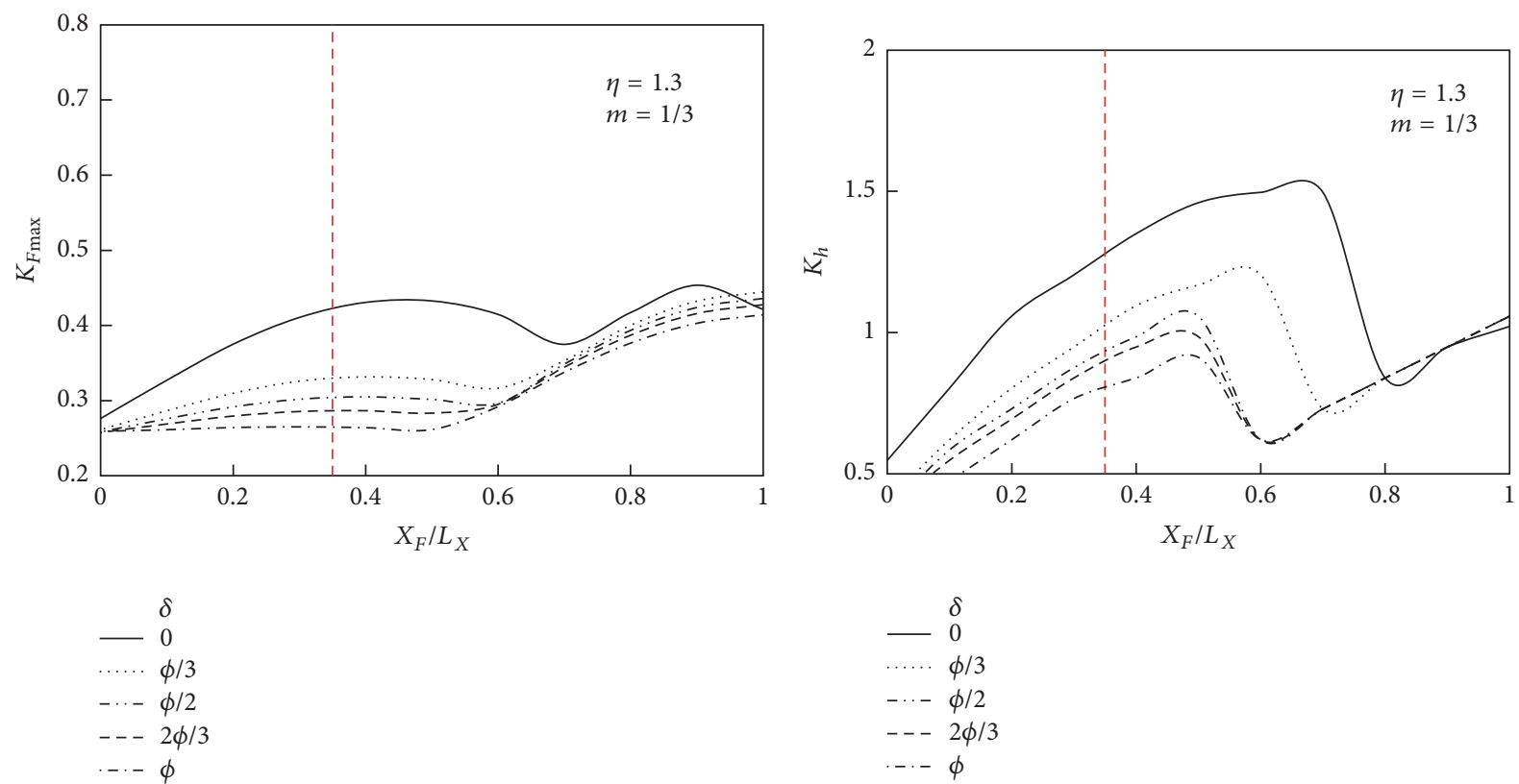

(a1)
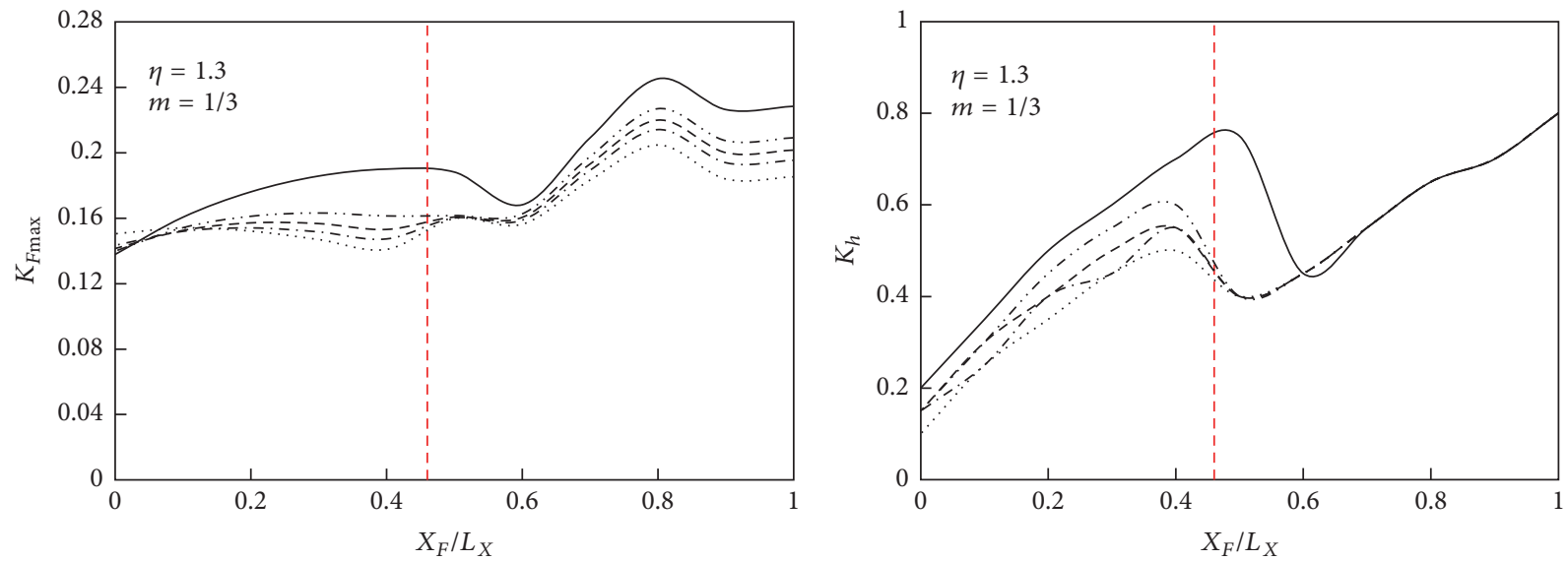

$$
\begin{array}{ll} 
& \delta \\
- & 0 \\
-\cdots- & \phi / 3 \\
--- & \phi / 2 \\
\cdots-- & 2 \phi / 3 \\
\cdots \cdots & \phi
\end{array}
$$$$
\begin{array}{ll} 
& \delta \\
- & 0 \\
-\cdots- & \phi / 3 \\
--- & \phi / 2 \\
-.- & 2 \phi / 3 \\
\ldots \ldots & \phi
\end{array}
$$

(b1)

(b2)

Figure 11: Effects of $\delta$ and $X_{F} / L_{X}$ on $K_{F \max }$ and corresponding $K_{h}:((\mathrm{a} 1)$ and (a2)) slope example in Figure 3; ((b1) and (b2)) slope example in Figure 9.

$$
\begin{aligned}
f_{9} & =\frac{r_{h p 2} s_{2}\left(2 r_{h p 2} \cos \theta_{h p 2}+s_{2}\right) \sin \theta_{h}}{6 r_{0 p 2}^{3}} \\
f_{10} & =\frac{L_{3}\left[r_{0 p 2} \sin \theta_{0 p 2}-h+\tan \beta\left(r_{h p 2} \cos \theta_{h p 2}+L_{3}+s_{2}\right)\right]\left[2\left(r_{h p 2} \cos \theta_{h p 2}+s_{2}\right)+L_{3}\right]}{6 r_{0 p 2}^{3}} \\
f_{11} & =-\frac{\cos ^{2} \theta_{0 p 2} h}{3 r_{0 p 2}} .
\end{aligned}
$$




\section{Notation}

c: $\quad$ Cohesion of soil

$c_{d}$ : Cohesion of soil considering the shear strength reduction coefficient

$E$ : Internal energy dissipation rate, where subscript $d 1$ denotes the upslope of the pile row and $d 2$ and $d 3$ denote the downslope of the pile row when $s_{1} \leq H / \tan \beta$ and $s_{1}>H / \tan \beta$, respectively

$F$ : $\quad$ Concentrated force per unit width out of plane on a pile because of the lateral soil movement, where subscripts $a, p 1$ and $p 2$ represent the upslope thrust force and downslope resistance when $s_{1} \leq H / \tan \beta$ and $s_{1}>H / \tan \beta$, respectively

$F_{n}$ : Horizontal component of the net force on the part of the pile above the potential slip surface

$F_{s}: \quad$ Factor of safety or the shear strength reduction coefficient

$f_{i}$ : Derivation coefficient of the gravity work rate, $i=1,2,3, \ldots, 11$

$h$ : Depth of the potential slip surface below the pile top

$h_{c}$ : Depth of the critical slip surface below the pile top

$H$ : Height of the slope

$K_{F}: \quad$ Ratio of $F_{n}$ over $0.5 \gamma H^{2}$

$K_{F t}$ : Ratio of the horizontal component of the net force on the pile top over $0.5 \gamma \mathrm{H}^{2}$

$K_{F \max }$ : Ratio of the horizontal component of the net limiting force on the pile over $0.5 \gamma \mathrm{H}^{2}$

$K_{h}$ : $\quad$ Ratio of the depth of the critical slip surface below the pile top over $H$

$L_{1}$ : Horizontal distance from the pile top to the outside edge of the slope crest

$L_{2}$ : Horizontal distance from the outside edge of the slope crest to the intersection between the potential slip surface in the upslope of the piles and the slope crest

$L_{3}$ : Horizontal distance from the pile top to the toe of slope if $s_{1}>H / \tan \beta$

$L_{X}$ : Horizontal projection length of the slope face

$m$ : Ratio of the vertical distance from the action point of the concentrated force on the pile to the potential slip surface over $h$

$r$ : $\quad$ Radius of any point on a log-spiral slip line, where subscripts $0 a$ and ha denote the start and end in the upslope of the pile row; $0 p 1, h p 1$ and $0 p 2, h p 2$ denote those in the downslope of the pile row when $s_{1} \leq H / \tan \beta$ and $s_{1}>H / \tan \beta$, respectively

$s_{1}$ : Horizontal distance from the pile top to the intersection between the slope face and the potential slip surface in the downslope of the piles $s_{2}$ : Horizontal distance from the toe of the slope to the intersection between the zone outside the toe and the potential slip surface in the downslope of the piles

$W$ : Work rates of external forces, where subscripts $F a$ and $G a$ denote the upslope thrust force and gravity in the upslope of the piles; Fp1, Gp1 and Fp2, Gp2 denote the downslope resistance and gravity in the downslope of the piles when $s_{1} \leq H / \tan \beta$ and $s_{1}>H / \tan \beta$, respectively

$X_{F}$ : Horizontal distance from the pile top to the toe of the slope in general cases

$X_{F C}$ : Value of $X_{F}$ if there is a critical failure state when the soil mass in the upslope of the pile row surpasses the pile top

$z$ : Depth from action point of the concentrated force on the pile to its top, where subscripts $a, p 1$, and $p 2$ denote the upslope thrust force and downslope resistance when $s_{1} \leq H / \tan \beta$ and $s_{1}>H / \tan \beta$, respectively

$\beta$ : $\quad$ Dip angle of the slope face

$\gamma$ : Unit weight of the soil

$\delta$ : $\quad$ Dip angle of the net limiting force on the pile, where subscripts $a, p 1$, and $p 2$ denote the dip angle of the upslope thrust force and downslope resistance when $s_{1} \leq H / \tan \beta$ and $s_{1}>H / \tan \beta$, respectively (see Figure 1 )

$\phi$ : Internal friction angle of the soil

$\phi_{d}$ : Internal friction angle of soil considering the shear strength reduction coefficient

$\eta$ : $\quad$ Stability improvement coefficient of the slope that is reinforced with piles

$\theta$ : $\quad$ Rotation angle of any point on a log-spiral slip line, where subscripts $0 a$ and $h a$ denote the start and end in the upslope of the pile row; $0 p 1, h p 1$ and $0 p 2, h p 2$ denote those in the downslope of the pile row when $s_{1} \leq H / \tan \beta$ and $s_{1}>H / \tan \beta$, respectively

$\omega$ : Angle acceleration of the kinematical soil body, where subscripts $a, p 1$, and $p 2$ denote the soil mass in the upslope of the pile row and that in the downslope of the pile row when $s_{1} \leq H / \tan \beta$ and $s_{1}>H / \tan \beta$, respectively.

\section{Competing Interests}

The authors declare that there is no conflict of interests regarding the publication of this paper.

\section{Acknowledgments}

The research was supported by the National Natural Science Foundation of China (Grants nos. 51278430 and 51578466) 
and the Program for New Century Excellent Talents in University (NCET-13-0976). The authors are also grateful to Dr. Wei Dong Guo for his generous assistance.

\section{References}

[1] T. Ito and T. Matsui, "Methods to estimate lateral force acting on stabilizing piles," Soils and Foundations, vol. 15, no. 4, pp. 43-59, 1975.

[2] T. Ito, T. Matsui, and W. P. Hong, "Design method for stabilizing piles against landslide-one row of piles," Soils and Foundations, vol. 21, no. 1, pp. 21-37, 1981.

[3] C. Y. Lee, T. S. Hull, and H. G. Poulos, "Simplified pile-slope stability analysis," Computers and Geotechnics, vol. 17, no. 1, pp. 1-16, 1995.

[4] S. Hassiotis, J. L. Chameau, and M. Gunaratne, "Design method for stabilization of slopes with piles," Journal of Geotechnical Engineering, vol. 123, no. 4, pp. 314-323, 1997.

[5] Y. He, H. Hazarika, N. Yasufuku, and Z. Han, "Evaluating the effect of slope angle on the distribution of the soil-pile pressure acting on stabilizing piles in sandy slopes," Computers and Geotechnics, vol. 69, pp. 153-165, 2015.

[6] H. G. Poulos, "Design of reinforcing piles to increase slope stability," Canadian Geotechnical Journal, vol. 32, no. 5, pp. 808818, 1995.

[7] L. Chen and H. G. Poulos, "Analysis of pile-soil interaction under lateral loading using infinite and finite elements," Computers and Geotechnics, vol. 15, no. 4, pp. 189-220, 1993.

[8] Y. K. Chow, "Analysis of piles used for slope stabilization," International Journal for Numerical and Analytical Methods in Geomechanics, vol. 20, no. 9, pp. 635-646, 1996.

[9] F. Cai and K. Ugai, "Numerical analysis of the stability of a slope reinforced with piles," Soils and Foundations, vol. 40, no. 1, pp. 73-84, 2000.

[10] C.-Y. Chen and G. R. Martin, "Soil - Structure interaction for landslide stabilizing piles," Computers and Geotechnics, vol. 29, no. 5, pp. 363-386, 2002.

[11] S. Jeong, B. Kim, J. Won, and J. Lee, "Uncoupled analysis of stabilizing piles in weathered slopes," Computers and Geotechnics, vol. 30, no. 8, pp. 671-682, 2003.

[12] J. Won, K. You, S. Jeong, and S. Kim, "Coupled effects in stability analysis of pile-slope systems," Computers and Geotechnics, vol. 32, no. 4, pp. 304-315, 2005.

[13] E. Ausilio, E. Conte, and G. Dente, "Stability analysis of slopes reinforced with piles," Computers and Geotechnics, vol. 28, no. 8, pp. 591-611, 2001.

[14] R. L. Michalowski, "Stability of uniformly reinforced slopes," Journal of Geotechnical and Geoenvironmental Engineering, vol. 123, no. 6, pp. 546-556, 1997.

[15] T. K. Nian, G. Q. Chen, M. T. Luan, Q. Yang, and D. F. Zheng, "Limit analysis of the stability of slopes reinforced with piles against landslide in nonhomogeneous and anisotropic soils," Canadian Geotechnical Journal, vol. 45, no. 8, pp. 1092-1103, 2008.

[16] X. Li, X. Pei, M. Gutierrez, and S. He, "Optimal location of piles in slope stabilization by limit analysis," Acta Geotechnica, vol. 7, no. 3, pp. 253-259, 2012.

[17] T. Yamagami, J. Jiang, and K. Ueno, "A limit equilibrium stability analysis of slopes with stabilizing piles," in Slope Stability 2000, ASCE Geotechnical Special Publication 101, pp. 343-354, ASCE, 2000.
[18] W. D. Guo, "On limiting force profile, slip depth and response of lateral piles," Computers and Geotechnics, vol. 33, no. 1, pp. 47-67, 2006.

[19] E. Conte, A. Troncone, and M. Vena, "Nonlinear threedimensional analysis of reinforced concrete piles subjected to horizontal loading," Computers and Geotechnics, vol. 49, pp. 123-133, 2013.

[20] W. F. Chen, Limit Analysis and Soil Plasticity, Elsevier Science, Amsterdam, The Netherlands, 1975.

[21] H. S. Yu, R. Salgado, S. W. Sloan, and J. M. Kim, "Limit analysis versus limit equilibrium for slope stability," Journal of Geotechnical and Geoenvironmental Engineering, vol. 124, no. 1, pp. 1-11, 1998. 


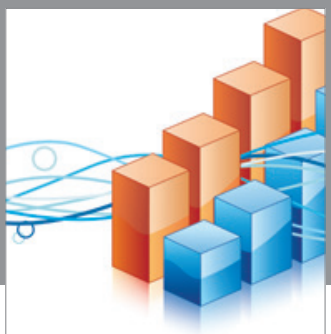

Advances in

Operations Research

vatem alat4

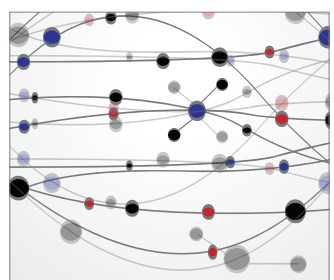

\section{The Scientific} World Journal
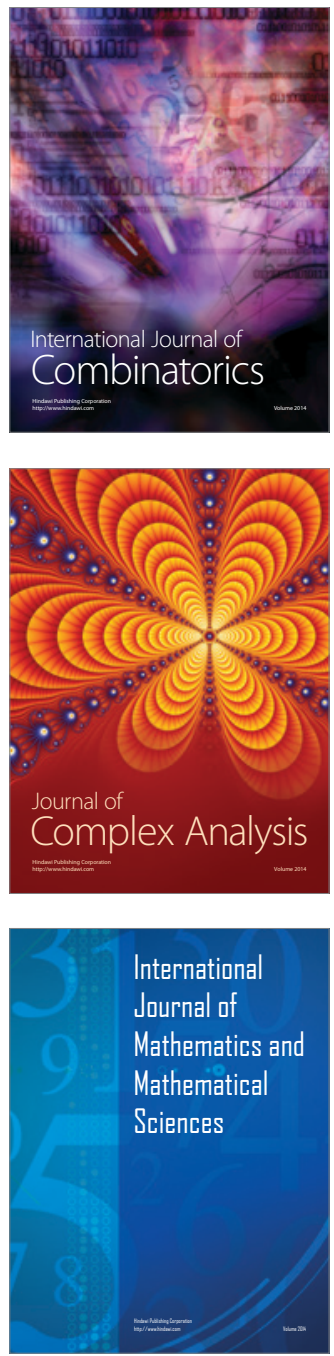
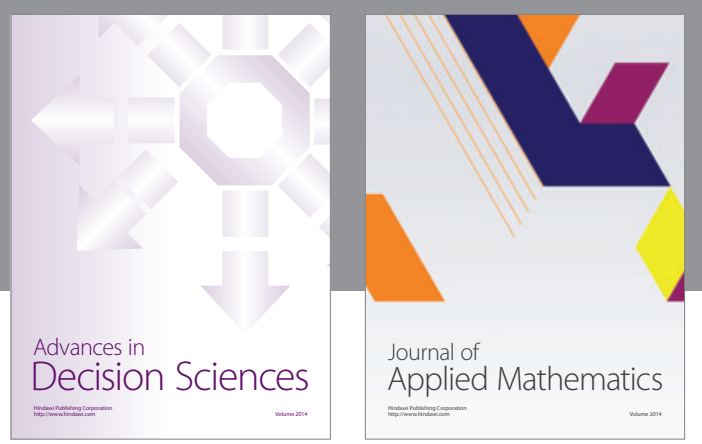

Algebra

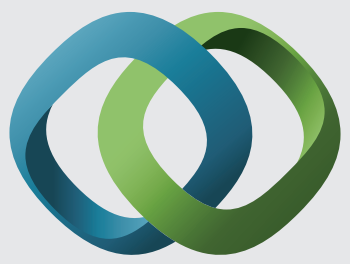

\section{Hindawi}

Submit your manuscripts at

http://www.hindawi.com
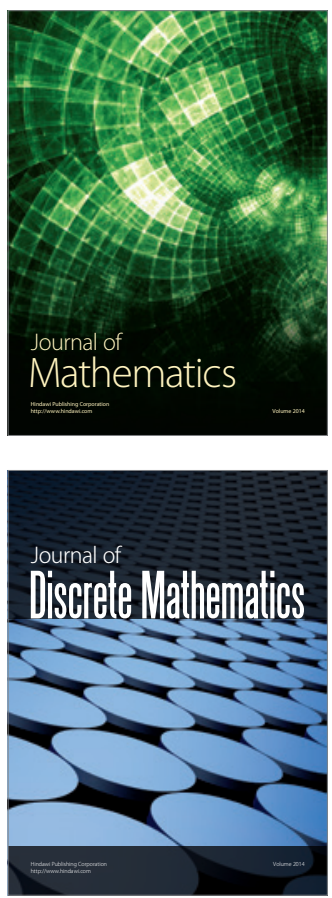

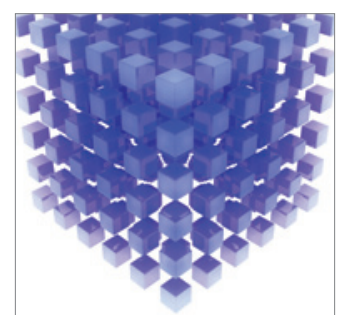

Mathematical Problems in Engineering
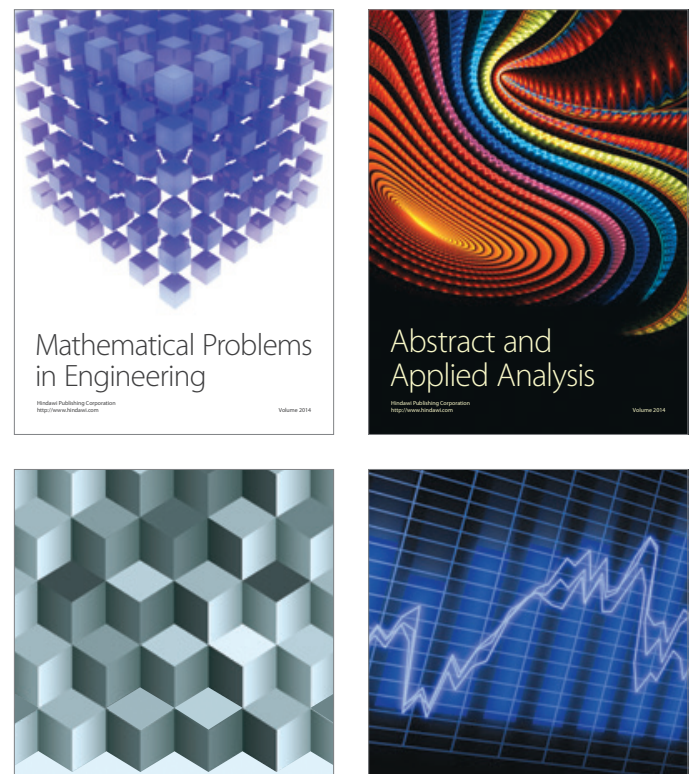

Journal of

Function Spaces

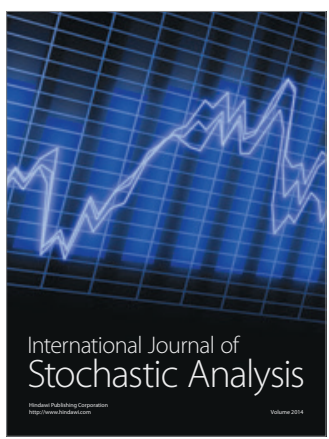

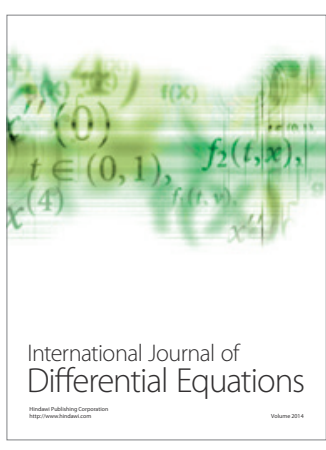
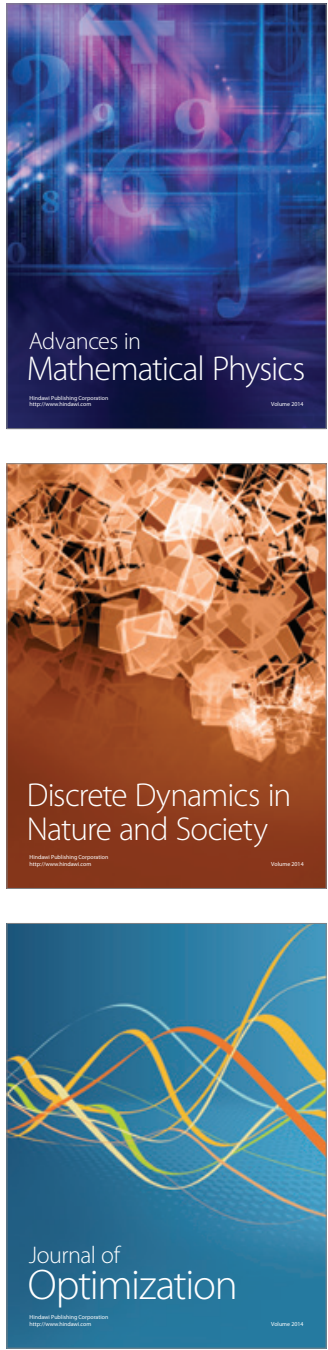